See discussions, stats, and author profiles for this publication at: https://www.researchgate.net/publication/334641292

The impact of assistive technology use for students with disabilities in higher education: a systematic review

Article in Disability and Rehabilitation Assistive Technology · July 2019

DOI: 10.1080/17483107.2019.1642395

CITATIONS

3

4 authors:

Aoife McNicholl

Dublin City University

3 PUBLICATIONS 3 CITATIONS

SEE PROFILE

Deirdre Desmond

National University of Ireland, Maynooth

66 PUBLICATIONS 1,160 CITATIONS

SEE PROFILE

Some of the authors of this publication are also working on these related projects:

CERVIVA ICE View project

Children's participation in shared decision making View project
Hannah Casey

National University of Ireland, Maynooth

1 PUBLICATION 3 CITATIONS

SEE PROFILE

Pamela Gallagher

Dublin City University

124 PUBLICATIONS 2,167 CITATIONS

SEE PROFILE 


\section{The impact of assistive technology use for students with disabilities in higher education: a systematic review}

\section{Aoife McNicholl, Hannah Casey, Deirdre Desmond \& Pamela Gallagher}

To cite this article: Aoife McNicholl, Hannah Casey, Deirdre Desmond \& Pamela Gallagher (2019): The impact of assistive technology use for students with disabilities in higher education: a systematic review, Disability and Rehabilitation: Assistive Technology, DOI: $\underline{10.1080 / 17483107.2019 .1642395}$

To link to this article: https://doi.org/10.1080/17483107.2019.1642395

\section{曲 Published online: 23 Jul 2019.}

\section{Submit your article to this journal $\llbracket$}

山 Article views: 23

View Crossmark data ¿ 


\title{
The impact of assistive technology use for students with disabilities in higher education: a systematic review
}

\author{
Aoife McNicholl $^{\mathrm{a}}$ (D), Hannah Casey ${ }^{\mathrm{b}}$, Deirdre Desmond ${ }^{\mathrm{b}}$ (D) and Pamela Gallagher ${ }^{\mathrm{a}}$ \\ ${ }^{\mathrm{a} S}$ School of Nursing and Human Sciences, Dublin City University, Dublin, Ireland; ${ }^{\mathrm{b}}$ Department of Psychology, Assisting Living and Learning \\ Institute, Maynooth University, Maynooth, Ireland
}

\begin{abstract}
Purpose: This systematic review examines the impact of assistive technology (AT) on educational and psychosocial outcomes for students with disabilities (SWDs) in higher education.

Materials and methods: Qualitative, quantitative and mixed method studies were identified through systematic searches of five databases: PsycINFO, PubMed, CINAHL, ERIC and Web of Science (Social Science Citation Index). The search was conducted in January 2018. Thematic synthesis was carried out to collate findings across papers and the methodological quality of included papers was assessed using a Mixed Methods Appraisal Tool (MMAT).

Results: Twenty-six papers were included for analysis. Four analytic themes were identified; "AT as an enabler of academic engagement"; "barriers to effective AT use can hinder academic engagement"; "the transformative possibilities of AT from a psychological perspective"; and "AT as an enabler of participation".

Conclusions: This systematic review identifies that AT can promote educational, psychological and social benefits for SWD. However, AT users and AT officers must be aware of certain factors, such as inadequate AT training, inadequacies of devices, availability of external support and the challenge of negotiating multiple information sources, can hinder effective AT use and thus restrict engagement in the higher education environment. Future AT practices should focus on harnessing the potential of mainstream devices as AT for all students, thus facilitating inclusion and reducing stigma.
\end{abstract}

> IMPLICATIONS FOR REHABILITATION

- Students with disabilities face academic, psychological and social challenges within the higher education environment.

- Assistive technology (AT) use can enable academic engagement and social participation and be transformative from a psychological perspective.

- Disability support staff in higher education should ensure that the AT needs of students with disabilities are met in order to enhance the educational experience.

- Harnessing the potential of mainstream devices as AT for all students will facilitate inclusion and reduce stigma.

\section{ARTICLE HISTORY}

Received 29 November 2018

Revised 18 June 2019

Accepted 8 July 2019

\section{KEYWORDS}

Assistive technology; education; psychosocial; students; disability

\section{Introduction}

Assistive technology (AT) is defined as "any product whose primary purpose is to maintain or improve an individual's functioning and independence and thereby promote their wellbeing" [1]. For people with disabilities, AT has the potential to improve functioning, reduce activity limitations, promote social inclusion, and increase participation in education, the Labour market and civic life. AT has been recognized as a human right in the United Nations Convention on the Rights of Persons with Disabilities (UNCRPD) [2]. Traditionally, the benefits or outcomes of AT have been viewed as self-evident by funding bodies and those who provide AT services [3]. This has resulted in a relative gap in evidence for the impact of AT on key outcomes such as participation and quality of life [4] but there is also growing acknowledgement that research needs to focus on impacts in user-valued domains [5].

Internationally, an increasing number of students with disabilities (SWDs) are accessing and actively participating in education.
Data from the European Commission [6], for example, indicate that over three quarters of children with disabilities are enrolled in mainstream schools in Portugal, Spain, Ireland and Italy. In the USA, increasing levels of engagement have also been documented, with $65.8 \%$ of SWDs participating substantially, if not fully, within mainstream public school classrooms in 2014 compared with $51.5 \%$ in 2004 [7]. Research at primary and post-primary school levels indicates that AT is a significant factor in contributing to this change, improving both educational participation and subjective well-being [8-10].

With widening access in primary and post-primary education, demand and opportunities for third level participation continue to grow. European figures show that the percentage of students studying in higher education who indicated they had a disability or impairment was $25 \%$ or above in the Netherlands, Lithuania and Ukraine [11]. In the UK, participation rates have been steadily increasing with SWDs comprising $11.3 \%$ of the total 
undergraduate population in 2013 versus $7.1 \%$ in 2004 [12]. A similar trend has been observed in the USA [7].

While the increasing participation of SWDs in higher education points to more inclusive education systems, SWDs still face academic, psychological and social challenges. Some disabilities affect students' capacities to actively engage in coursework, others affect students' abilities to move freely around campus. These types of difficulties are exacerbated in the organizational and structural characteristics of higher education environments e.g., large numbers of students in noisy lecture theatres, buildings with poor accessibility [13-15]. As a result, increased effort is needed on the part of SWDs in order to achieve their academic goals $[14,16,17]$. SWDs have lower levels of participation in extracurricular activities in higher education [17]; in some cases, the extra time expended in academic endeavours limits opportunities for social interactions outside of the classroom [14]. Social stigma is a major challenge to integration within tertiary institutions and is exacerbated by a lack of understanding of disabilities by the wider higher education population. This can increase an individual's sense of isolation and reduce their willingness to disclose their disability in an attempt to "fit in" among their peers [14-16,18-20].

Given the growing numbers of SWDs participating in higher education, the additional challenges faced by some students and the potential for AT to promote participation [21], there is a clear need for better understanding of the impacts of AT in higher education. To date, systematic reviews have focused on examining the impact and use of specific AT devices or have considered AT broadly but among specific user groups, rather than within specific contexts [22-24]. Two systematic reviews have explored AT within higher education settings among students with learning disabilities and dyslexia, respectively $[25,26]$. The aim of this review is to examine the impact of AT use on educational and psychosocial outcomes among SWDs in higher education. By considering the weight of evidence across diagnostic boundaries and AT classifications, this review will provide a comprehensive description of the impact of AT use on educational and psychosocial outcomes among SWD in higher education. Systematically identifying the potential benefits of AT in these areas could have important implications for the AT user themselves, while also informing AT-related funding, practices and policy in higher education.

\section{Materials and method}

\section{Search strategy}

In accordance with PRISMA guidelines [27], a systematic search of the literature on the educational and/or psychosocial impacts of AT use for those with disabilities in higher education was conducted. Five databases were searched: PsycINFO, PubMed, CINAHL, ERIC and Web of Science (Social Sciences Citation Index; $\mathrm{SSCl}$ ). Four were searched using a combination of indexed and free text terms (i.e., PsycINFO, PubMed, CINAHL and ERIC). Web of Science (SSCl) was searched using free text terms only. See appendices for detailed search strategies: PsycINFO (Appendix 1), PubMed (Appendix 2), CINAHL (Appendix 3), ERIC (Appendix 4) and Web of Science (SSCI) (Appendix 5). The reference lists of eligible papers were also searched.

Searches were limited to English language, peer-reviewed papers during the time period 1 January 2007 to 26 January 2018. We restricted the review to this period given the changing profile of higher education enrolments, the rapid technological developments of the past decade, the increasing availability and affordability of AT and the landmark publication of the UNCRPD in 2007. Details on the number of papers present at each phase of the review process can be seen in the PRISMA Flow Diagram in Figure 1. This diagram is a graphical representation of the number of papers identified in the systematic search and details the numbers of papers included at the title and abstract screening, fulltext screening and systematic review phases. It also details the numbers of duplicates removed and papers excluded and the reasons for exclusion of full-text papers.

\section{Selection criteria}

For the purposes of this review, disability is defined as "a state of decreased functioning associated with disease, disorder, injury, or other health conditions, which in the context of one's environment is experienced as an impairment, activity limitation, or participation restriction" [28, p. 1220]. Papers were deemed eligible for inclusion if they examined the impact of AT on at least one educational or psychosocial outcome. Educational outcomes were defined as any variables related to a student's academic engagement in a higher education setting. Psychosocial outcomes were defined as any variables relevant to an individual's psychological and/or social functioning within a higher education context. See Table 1 for detailed information on inclusion and exclusion criteria.

\section{Data extraction and synthesis}

Screening of titles and abstracts of eligible papers was undertaken by two reviewers (AMN and $\mathrm{HC}$ ). Full texts of remaining papers were then read by the same reviewers (AMN and $\mathrm{HC}$ ) and agreement was reached to exclude further papers that did not meet inclusion criteria. For all stages, any differences in opinion were resolved through consensus or discussion with a third and fourth review author (PG and DD). The reasons for exclusions at the fulltext stage were recorded (see Figure 1). The following was extracted from each paper: author and country of origin; study design; sample size, disability type and AT type; and results relevant to the research question (see Table 2).

Given the complexity and diversity of data within mixedmethod systematic reviews, there is no one gold standard synthesis design or method of analysis. Multiple approaches can be taken and are often informed by the research question and type of data extracted from primary studies [29-31]. A data-based convergent design was adopted in this study; all quantitative and qualitative data were analysed using the same synthesis method, namely thematic synthesis [32]. The suitability of this type of synthesis for diverse forms of evidence has been noted in the literature [33-36].

Thomas and Harden's [32] 3-staged approach to thematic synthesis was undertaken by AMN with independent review of themes by PG and DD, followed by group discussion to clarify and refine interpretations. First, data relevant to the research question from the results sections of all studies were coded line by line. In the case of quantitative data, codes were developed from the narrative descriptions of statistical analyses. Next, similar codes were organized together into descriptive themes. The final stage involved the development of the descriptive themes into analytic themes.

\section{Quality appraisal}

All 26 papers were quality appraised using the Mixed Methods Appraisal Tool (MMAT - version 2011) [37]. The MMAT was 
Papers identified through search strategy $(n=3,890)$ PsycINFO ( $n=609)$, PubMed $(n=1,033)$, CINAHL ( $n=$ 746), Web of Science SSCI $(n=756)$, ERIC $(n=746)$
Duplicates removed

$(n=1,157)$

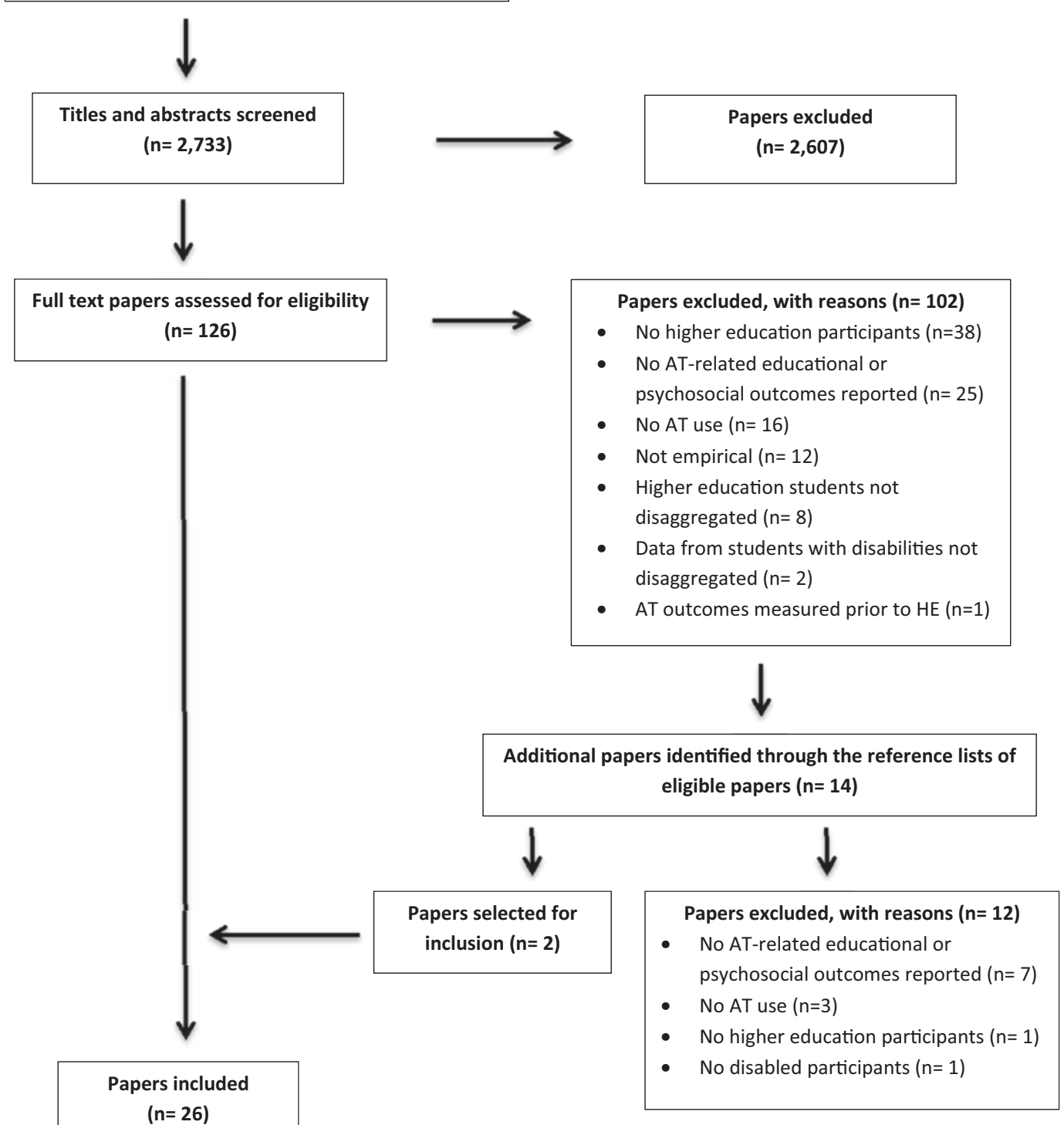

Figure 1. PRISMA diagram of the number of papers present at each stage of the systematic review process.

Table 1. Inclusion/exclusion criteria.

Inclusion criteria

Exclusion criteria

- Participants have a disability (any type), require and/or use any type of AT - Absence of disability among participants and are current higher education students (or where data for this group could be clearly disaggregated from other reported data)

- $\quad$ AT-related educational and/or psychosocial outcomes are examined

- Qualitative, quantitative or mixed method papers

- $\quad$ Papers in the English language

- Empirical, peer reviewed

specifically designed for use in systematic mixed studies reviews and allows the appraisal of quantitative, qualitative and mixed method papers using one tool [38]. This tool has demonstrated good reliability and efficiency and was shown to be the most consistent when compared with other tools which allow appraisal of multiple study types $[39,40]$. It has also been used widely in other systematic mixed studies reviews [41-45].
In the MMAT, the first stage involves assessing all papers suitability for further appraisal using two screening questions; whether the paper has clear research questions and if the data collection method was appropriate to answer these research questions. There are three response categories; "Yes", "No", "Can't tell". If both screening questions meet the criteria ("Yes" response), then further appraisal is considered appropriate. The 


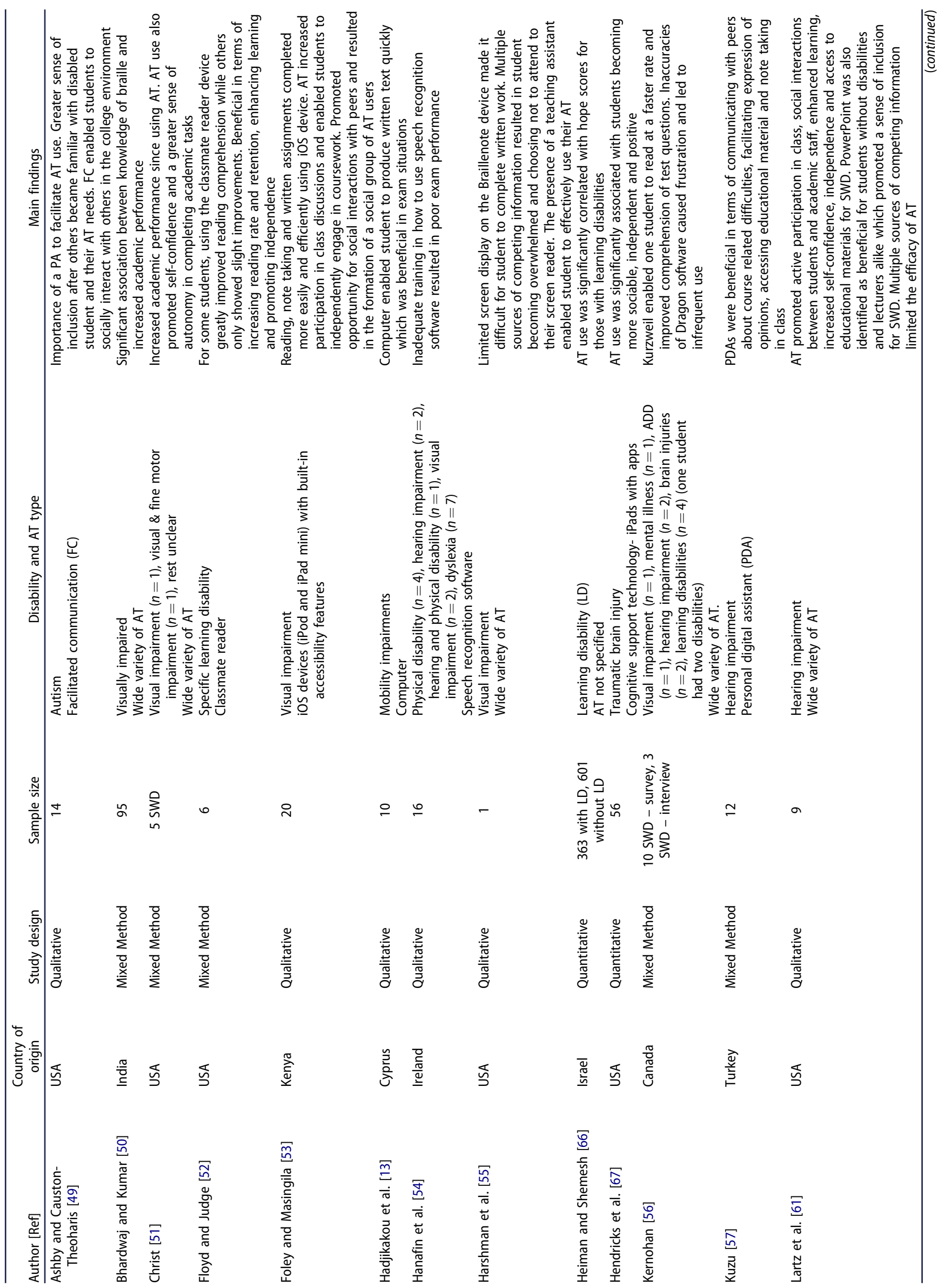




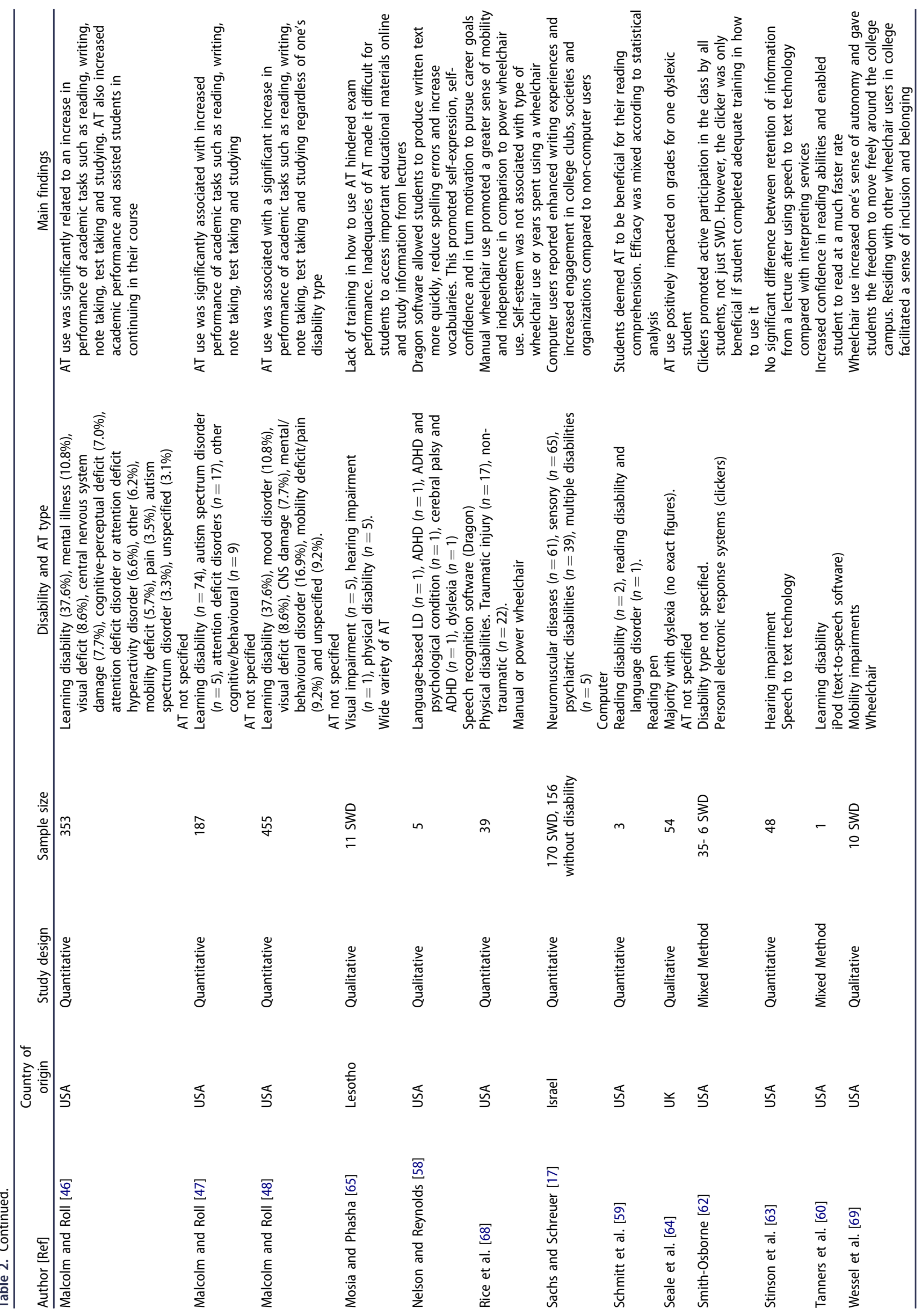


Table 3. AT and Disability types examined across included studies.

\begin{tabular}{|c|c|c|c|}
\hline Disability type & No. of papers & AT type & No. of papers \\
\hline Learning disability $[52,59,60,64,66]$ & 5 & iOS devices with accessibility features and/or apps $[53,60,67]$ & 3 \\
\hline Visual impairments $[50,53,55]$ & 3 & Wheelchair $[68,69]$ & 2 \\
\hline Hearing impairments $[57,61,63]$ & 3 & Speech recognition software $[54,58]$ & 2 \\
\hline Physical disabilities $[13,68,69]$ & 3 & Reading devices $[52,59]$ & 2 \\
\hline Autism [49] & 1 & Computers $[13,17]$ & 2 \\
\hline Traumatic brain injury [67] & 1 & Facilitated communication [49] & 1 \\
\hline Variety of diagnoses $[17,46,47,48,54,56,58,65]$ & 8 & Captioning software [63] & 1 \\
\hline \multirow[t]{4}{*}{ Not specified $[51,62]$} & 2 & Personal electronic response system [62] & 1 \\
\hline & & Personal digital assistants (PDA) [57] & 1 \\
\hline & & Variety of different ATs $[50,51,55,56,61,65]$ & 6 \\
\hline & & Not specified $[46,47,48,64,66]$ & 5 \\
\hline
\end{tabular}

Table 4. Quality scores for included studies using the Mixed Methods Appraisal Tool (MMAT).

\begin{tabular}{|c|c|c|c|}
\hline$\underline{\text { Study design }}$ & Criteria met* & Criteria not met/cannot tell* & Overall MMAT score (\%) \\
\hline \multicolumn{4}{|l|}{ Quantitative non-randomized } \\
\hline Heiman and Shemesh [66] & $3.1,3.2,3.3,3.4$ & & 100 \\
\hline Hendricks et al. [67] & $3.1,3.3 * *$ & $3.2,3.4$ & 50 \\
\hline Malcolm and Roll [46] & $3.1,3.2,3.3^{* *}, 3.4$ & & 100 \\
\hline Malcolm and Roll [47] & $3.1,3.2,3.3 * *, 3.4$ & & 100 \\
\hline Malcolm and Roll [48] & $3.1,3.2,3.3^{* *}, 3.4$ & & 100 \\
\hline Sachs and Schreuer [17] & $3.1,3.2,3.3,3.4$ & & 100 \\
\hline Schmitt et al. [59] & $3.1,3.2,3.3^{* *}, 3.4$ & & 100 \\
\hline Stinson et al. [63] & $3.2,3.3^{* *}$ & $3.1,3.4$ & 50 \\
\hline \multicolumn{4}{|l|}{ Quantitative descriptive } \\
\hline Rice et al. [68] & $4.1,4.3$ & $4.2,4.4$ & 50 \\
\hline \multicolumn{4}{|l|}{ Qualitative } \\
\hline Ashby and Causton-Theoharis [49] & $1.1,1.2,1.3$ & 1.4 & 75 \\
\hline Foley and Masingila [53] & $1.2,1.3,1.4$ & 1.1 & 75 \\
\hline Hadjikakou et al. [13] & $1.1,1.2,1.3$ & 1.4 & 75 \\
\hline Hanafin et al. [54] & $1.1,1.2,1.3$ & 1.4 & 75 \\
\hline Harshman et al. [55] & $1.1,1.2,1.3$ & 1.4 & 75 \\
\hline Lartz et al. [61] & $1.1,1.2,1.3$ & 1.4 & 75 \\
\hline Mosia and Phasha [65] & $1.1,1.2,1.3$ & 1.4 & 75 \\
\hline Nelson and Reynolds [58] & $1.1,1.3$ & $1.2,1.4$ & 50 \\
\hline Seale et al. [64] & $1.1,1.2$ & $1.3,1.4$ & 50 \\
\hline Wessel et al. [69] & $1.1,1.2,1.3,1.4$ & & 100 \\
\hline \multicolumn{4}{|l|}{ Mixed method } \\
\hline Bhardwaj and Kumar [50] & $1.3,4.1,4.2,5.1$ & $1.1,1.2,1.4,4.3,4.4,5.2,5.3$ & 25 \\
\hline Christ [51] & $1.2,1.3,4.1,4.2,5.1,5.2$ & $1.1,1.4,4.3,4.4,5.3$ & 50 \\
\hline Floyd and Judge [52] & $1.1,1.2,1.3,3.1,3.2,3.3^{* *}, 3.4,5.1$ & $1.4,5.2,5.3$ & 50 \\
\hline Kernohan [56] & $1.1,1.2,1.3,1.4,4.1,4.4,5.1,5.2$ & $4.2,4.3,5.3$ & 50 \\
\hline Kuzu [57] & $1.1,1.2,1.3,1.4,4.1,4.3,5.1,5.2$ & $4.2,4.4,5.3$ & 50 \\
\hline Smith-Osborne [62] & $1.2,1.3,3.2,3.3^{* *}, 3.4,5.1$ & $1.1,1.4,3.1,5.2,5.3$ & 50 \\
\hline Tanners et al. [60] & $1.2,1.3,3.1,3.2,3.3^{* *}, 3.4,5.1,5.2$ & $1.1,1.4,5.3$ & 50 \\
\hline
\end{tabular}

*Full list of criteria can be downloaded from Pluye et al. [37]. **Criterion 3.3 was not applicable to some papers so instead another criterion was created as per Pluye et al. [37] guidelines. These papers were judged on the criterion "is the statistical analysis appropriate to answer the research question?".

next stage involves assessing the paper using the checklist relevant to the study design. The qualitative component and quantitative components each contain four criteria for assessing the paper while the mixed method component contains three criteria. Every criterion is assessed using the response categories "Yes", "No' or "Can't tell" and an overall score calculated for each paper ranging from $0 \%$ (no criteria met) to $100 \%$ (all criteria met). In the case of mixed method papers, the mixed method component is used in addition to the qualitative component and appropriate quantitative component and an overall score calculated.

\section{Results}

\section{Study and sample characteristics}

Twenty-six papers describing twenty-five studies were deemed eligible for inclusion. Sixteen papers were from the USA, two papers from Israel and one paper from Cyprus, Canada, India, Ireland, Kenya, Lesotho, Turkey and the UK, respectively. The studies included quantitative $(n=8)$, qualitative $(n=10)$ and mixed method $(n=7)$ designs.
Sample size varied across studies ranging from 1 to 964 participants. Some papers focused on singular but broad categories of diagnoses, other papers included participants with a variety of diagnoses and two did not specify the types of disabilities experienced by all participants. AT use also varied widely with some papers focusing on a specific category of AT, others reported on a variety of different ATs and some did not specify what type of AT was used. See Table 3 below for a full breakdown of AT and disability types across the papers.

\section{Quality assessment}

The quality appraisal of included papers is outlined in Table 4. Seven papers met $100 \%$ of the criteria, seven papers met $75 \%$ of the criteria, eleven papers were of adequate quality meeting $50 \%$ of the criteria and one paper was poor quality only meeting $25 \%$ of the criteria. Generally, the quality of mixed method papers was quite low with all studies failing to consider the limitations associated with integration. The majority of qualitative papers did not address reflexivity of the researcher. 


\section{Synthesis of results}

Using the process of thematic synthesis [32], four analytic themes were identified in the data. These were "AT as an enabler of academic engagement", "Barriers to effective AT use can hinder educational engagement", "The transformative possibilities of AT from a psychological perspective" and "AT as an enabler of participation". Each of the themes is reported in detail below.

\section{Theme 1: AT as an enabler of academic engagement}

AT has the potential to support SWD engagement with their academic work. This includes enabling SWD to perform common academic tasks more easily, allowing SWD to access and engage with educational material related to their course, increase their learning and promote improved academic performance. In some papers, AT was not only beneficial to SWD but also to students without disabilities and lecturers alike. In relation to academic engagement, AT was seen as an enabler but not driver of change across the papers; it made engagement easier rather than initiating it. It was viewed in a positive sense as an "enhancer" consistent with a right based universal model.

AT enabled SWD to complete common academic tasks more easily and efficiently. Two studies measured the impact of various different types of AT devices and found that AT use, in general, was associated with increased performance of educational tasks such as note taking, test taking, studying, reading and writing for SWD [46,47], regardless of one's disability type [48]. Other studies focused on the impact of specific AT devices on students' performance of academic tasks [13,17,49-60]. Computers significantly improved writing experiences for SWD in two studies $[13,17]$, as did speech recognition software in one paper, in terms of enabling students to produce written text more quickly, reducing spelling errors and promoting the use of wider vocabularies [58]. Reading pens, iPads (with text to speech feature enabled), Kurzweil, a classmate reader device and an iPod (with text to speech feature enabled) all positively impacted on students' reading ability in some way, with certain devices improving comprehension [52,59], while others increased reading rate and/or ease at which reading tasks could be completed $[52,53,56,60]$. The use of specific AT devices such as an iPad and PDA made note taking and subsequently revising for exams or completing assignments more convenient $[53,57]$.

AT also enhances learning and promotes engagement of SWD both inside and outside the classroom. Two papers found that the AT provided a visual representation of learning material which promoted active participation in the class $[61,62]$. Three papers found that AT enhanced learning $[17,52,61]$; in two of these papers AT increased retention of information [52,61]. One paper found no significant difference in information retention following a lecture between those who used speech-to-text services compared to those who used an interpreter [63]. Three papers found that SWD were able to access educational materials easily and conveniently through the use of iPads, PDAs and Mallard system which also facilitated their learning $[53,57,61]$.

Increased academic performance was another advantage of AT use for SWD. Eight papers reported that AT improved grades or enabled the SWD to perform better [46,50,51,55,58,60,61,64], while the majority of SWD in one paper report that AT enabled them to persist in their course of study [46].

AT is not only beneficial for SWD, but also for students without disabilities and academic staff. The use of PowerPoint and clickers was considered to be advantageous for all students regardless of whether they had a disability or not $[61,62]$. One paper also mentioned the benefits of AT for facilitating a lecturer's engagement with the topic [61]. While the other papers did not explicitly mention the benefits of AT for those without disabilities, many of the papers examined the use of generic devices as AT, which have the potential to be used by anyone for educational purposes.

\section{Theme 2: Barriers to effective AT use can hinder educational} engagement

Predominantly, AT use was positive for SWD academic engagement as described above. However, there were certain situations identified across the papers when AT could not be used effectively by SWD and this hindered their educational engagement. These included inadequate training for SWD, inadequacies of devices themselves, difficulty in negotiating multiple sources of competing information and the unavailability of appropriate support from others to facilitate effective AT use.

Inadequate training in how to effectively use the AT was a significant barrier which hindered the educational engagement of SWD. Two papers reported that students were not adequately trained or familiar with the AT and as a result performed poorly in exams [54,65]. Two other papers found that the AT is only beneficial for educational engagement if the student completes adequate training $[58,62]$.

Inadequacies of ATs were another factor which hindered students' learning and performance. These included limited screen displays, outdated programmes, poor quality recordings, inability to selectively choose a portion of the recording to listen to and inaccuracies when using the device. Such inadequacies resulted in students using the device infrequently [56] and limited students' ability to complete written assignments quickly and efficiently, study information from lectures and access relevant educational materials online $[55,58,65]$.

Multiple sources of competing information were another factor that hindered the efficacy of AT devices. Two papers reported students becoming overwhelmed by multiple information sources and having difficulties concentrating, thus choosing not to attend to their screen reader [55] or depending on their interpreter to indicate the usefulness of PowerPoint during a lecture [61].

The presence of an individual to facilitate AT use was an essential factor in three papers $[49,55,61]$. The unavailability of appropriate support from a personal assistant, teaching assistant or interpreter made it difficult if not impossible for some SWD to engage in the academic task using the AT device $[49,55,61]$. This was dependent on the nature and severity of disability.

Theme 3: The transformative possibilities of AT from a psychological perspective

AT has the potential to facilitate positive psychological change for SWD. Across a number of papers, AT use was found to significantly contribute to psychological variables such as hope, confidence, motivation, sense of autonomy, self-expression and sense of belonging. In a number of papers, it was seen as the driver of positive psychological change; SWD were more autonomous, motivated and confident as a result of AT use. When AT was viewed in a positive sense as a tool of empowerment, it also had a positive effect on the mind-sets of those without disabilities, changing perceptions and reducing stigma. However, this seems to be contingent on the familiarity of others with the person with a disability and their AT use.

AT use empowers SWD to be more positive, confident and motivated. AT promoted hope and positivity for SWD in two papers $[66,67]$. The use of Powerpoint, smartboard, iPads, iPods, speech recognition software and screen reading software all increased the confidence of SWD in some way, with some devices 
enabling participation in class discussions [53,61], one device increasing confidence in one's reading abilities [60], while others promoted academic performance which resulted in greater selfconfidence [51,58]. In one paper, this sense of confidence was linked to increased motivation to continue writing and pursue career goals [58]. One paper found no significant relationship between type of wheelchair use or years spent using a wheelchair and self-esteem [68].

AT use also had a significant positive impact on participants' sense of autonomy. The use of PowerPoint, iPads, the classmate reader device and computer programmes enabled SWD to independently engage with and complete coursework [51-53,61]; iPads additionally afforded students with visual impairments a degree of privacy in their personal communications [53]. In one paper, this newfound sense of independence, afforded by speech recognition software, enabled SWD to easily self-express creatively while writing [58]. AT use also promoted feelings of independence and control in day to day college activities [51,67-69]. Two papers looked specifically at wheelchair use; one paper reported that manual wheelchair use promoted higher levels of cognitive independence and mobility compared with power wheelchair use [68]; while the other found that wheelchair use in general gave SWD a sense of freedom and autonomy to decide what they wanted to do and where they wanted to go [69].

AT use also affected participants' sense of belonging within the higher education environment. Feelings of inclusion were dependent on how others viewed SWD and their AT use. In one paper, SWD were an integral part of the college campus due to residing and integrating with others who also used wheelchairs [69]. The fact that these students had common, shared experienced because of their AT use probably facilitated this sense of belonging. Similarly, in another paper where both students with and without disabilities used the same AT device, SWD report feeling more included in the class [61]. In this case, SWD did not feel different because of their AT use as this device was viewed as being beneficial to all. Familiarity of others with the SWD and AT use seemed to be key in relation to creating an inclusive environment. Two papers reported that perceptions of others towards SWD and AT use became more positive once they were accustomed to the SWD and their AT [49,53], which in turn facilitated feelings of inclusion in the college campus [49]. In one paper where SWD used facilitated communication, some reported feeling socially isolated from their classmates in the beginning, while others were considered incompetent by university staff due to a lack of understanding of their AT needs, hampering their inclusion within their academic course [49].

\section{Theme 4: AT as an enabler of participation}

AT use was shown to increase social interactions, provide opportunities for learning support, promote active engagement with peers in course-related discussions, promote engagement in clubs or groups and encourage the creation of a social group of AT users across a number of papers. However, for those who depended on AT for communication purposes, the efficacy of interactions depended on the group size and personal assistants giving students personal space.

AT empowered SWD to interact more with others and engage with peers in course-related discussions. Five papers found that SWD became more sociable in general within the higher education environment due to AT use [49,53,67-69], with one paper specifying that it enabled the student to greet fellow classmates in the corridors [49], while another stated that AT use enabled SWD to make friends through social networking sites [53]. In two papers, SWD routinely used their AT for learning support in terms of communicating with their lecturers about problems they were experiencing [61] or asking peers for help in relation to their coursework [57]. One paper reported the usefulness of AT for dating purposes for a deaf student, but also as a convenient way of communicating with both peers and academic staff through instant messaging and email as most were not trained in sign language [61]. For course-related discussions, AT use facilitated students in expressing their opinions both in class [61] and online [53,57].

However, social interaction and group discussion were not as easy and straight forward for all SWD. Non-verbal autistic students, who used facilitated communication, found social integration difficult and often experienced social isolation [49]. The requirement for a personal assistant to be close by to support communication also restricted the development of natural peer interactions [49]. However, these students reported that small group discussions facilitated interaction with peers, giving students an opportunity to express their opinions through facilitated communication [49].

Another advantage of AT use was increased involvement in clubs and groups or the creation of new social groups. One paper found that computer users had more involvement with college clubs, societies and organizations than non-computer users [17]. AT users have shared experiences and something in common by virtue of the fact they use AT, which also creates the potential for a social group of AT users. This group could facilitate the inclusion of SWD, through identifying with others who are in a similar situation. Two papers refer to this, the first mentioning the social integration of wheelchair users within the same institution [69], the second referring to a social group of visually impaired students who use iPads daily in college [53]. In one paper, the social group of AT users not only enhanced students' social participation but also served as peer learning support for new AT users [53].

\section{Discussion}

This systematic review is the first to synthesize existing evidence on the impact of AT use by SWD in higher education. AT has significant positive impacts on academic engagement, psychological well-being and social participation. AT use was found to improve SWD performance of academic tasks, increase learning and engagement with educational materials and increase academic performance. Some papers also reported the benefits of AT for students without disabilities and academic staff. This demonstrates a shift in how AT should be viewed. AT is predominantly considered in relation to someone with a disability or impairment; as a device which can alleviate the burden or challenges associated with one's disability [70-74]. However, as a society, we need to re-evaluate this perception. AT is a powerful tool not only for SWD, but also for students without disabilities and academic staff alike. With advances in technologies over recent years, we are seeing a significant shift in what we term "AT", with mainstream devices now offering accessibility features $[75,76]$. The papers included in this systematic review exemplify this with eight papers examining the use of more generic devices, such as iPods, iPads, computers, PowerPoint, etc. as AT for educational engagement $[13,17,53,57,60-62,65]$. Moving forward, we need to integrate a universal design for learning approach with individual AT needs, to maximize the benefits for all, not just the SWD $[77,78]$. By doing this, AT can become more "normalised' within an academic setting, facilitating SWD desire to "fit in" with their peers $[14,16,18,20]$. Future research should explore what factors should 
be considered integrating individual AT needs with a universal design for learning approach.

The second theme found that barriers to effective AT use can hinder educational engagement. Such barriers included inadequate training, inadequacies of technologies themselves, difficulty in negotiating multiple sources of competing information and lack of appropriate support from others in using AT. These barriers can be understood with reference to the Matching Person and Technology (MPT) Model $[79,80]$. The MPT Model postulates that AT use depends on interactions between contextual (e.g., adequate training), person (e.g., functional abilities, personal preferences) and technology (e.g., capabilities of the device) factors. Careful attention to each of these factors is needed to optimize AT use. In particular, ensuring that the environment/context is supportive of AT is critical. Disability support services within the higher education environment are of utmost importance to SWD in promoting a sense of acceptance and belonging and ensuring the appropriate supports are received [14,81]. However, institutional policies and procedures can make it difficult for SWD to acquire the AT they need in a timely fashion [14,82] and unaccommodating lecturers can also inhibit AT use [19]. One significant challenge for SWD is the expectation for them to adapt and "fit in" to the existing learning environment regardless of individual requirements $[14,82]$. Adopting a Universal Design for Learning approach concurrently with supporting individual AT needs can help address this challenge by exposing students to a curriculum which is flexible to their preferences while also taking into account specific AT needs [77,82]. AT officers in higher education institutions who are cognizant of the interplay between contextual, person and technology factors, as outlined in the MPT, can ensure that the AT device is appropriate to individual needs and can be used effectively.

The third theme discusses how AT promotes positive psychological change for SWD. AT empowers SWD to be more confident, autonomous and motivated. AT is portrayed more as the driving force of psychological change, a tool of empowerment rather than enablement for SWD. In addition, when AT is viewed in a positive sense by others rather than as a tool to alleviate the burden of disability, it can facilitate inclusion and a sense of belonging in the higher education environment. AT viewed in this way was found to reduce stigma and change perceptions. This again points to the importance of "normalising" AT use, making it acceptable and realizing its potential benefits for all, in order to reduce stigma and facilitate inclusion [83]. Future research should explore in more detail the benefits of AT use for all and the factors that are important in relation to reducing stigma.

The fourth theme identified AT as an important enabler of participation in the higher education environment. AT facilitated peer related discussions surrounding course material, provided a means by which SWD could resolve course-related problems, promoted engagement in clubs and societies and provided the opportunity to form social groups of AT users. One key recommendation by AT experts and users alike is the creation of social networks of users. Potential benefits include opportunities to exchange ATrelated knowledge and reduce the risk of social isolation [76]. As identified from the systematic review, AT provides an opportunity for the formation of these social groups. However, these social groups of AT users need not exclusively consist of SWD. If we as a society can outline and promote the benefits of certain AT for all, it may not only enhance performance of academic tasks and learning, but may also provide additional opportunities for integration and more diverse social interactions. The increase in the availability of mainstream devices with accessibility features promotes universal access to assistive products [84], further promoting opportunities for social integration among all users of these devices. This is something which higher education institutions should focus on as a means of enhancing SWD overall educational experience as at present SWD report poorer quality of life than non-disabled peers and often experience isolation [14,15,19,85].

This systematic review has identified important directions for future research and potential ways in which higher education institutions should consider and integrate AT into the learning environment in order to optimize social and educational benefits for all. However, there are some limitations which must be considered. The review consists only of papers published in the English language. Thus, it is possible that some relevant papers may have been overlooked. In addition, we chose to only include papers which dealt with the views or experiences of current higher education students who are AT users; peers and academic staff may have additional useful information related to the impact of AT on SWD in higher education.

The limitations of thematic synthesis also need to be considered; including the findings of multiple studies together in one synthesis can mask the shortcomings of studies of low methodological quality [34]. There is potential for studies with low quality to contribute little unique material to the overall development of analytic themes within the synthesis, while studies of better methodological quality make the most contribution [32]. Another criticism of thematic synthesis is its focus on similarities within the data, often at the expense of identifying divergent results and gaps in the data [34]. In addition, some argue that combining qualitative studies together in one synthesis is inappropriate as the context of one study and setting does not apply to others [86]. However, through extraction and presentation of contextual information such as sample size, disability and AT type from each individual study, the reader can validate for themselves the claims made in the review.

In conclusion, this systematic review highlights the benefits of AT for academic engagement, psychological well-being and participation in a higher education environment for SWD. AT officers in particular need to be cognizant of the evolving nature of AT, and the potential for students to use more mainstream devices to meet their AT needs. This is, in turn, provides an opportunity for higher education institutions to promote the benefits of AT for all.

\section{Disclosure statement}

The authors report no conflicts of interest.

\section{ORCID}

Aoife McNicholl (D) http://orcid.org/0000-0002-1799-1483

Deirdre Desmond (D) http://orcid.org/0000-0002-6746-7006

Pamela Gallagher (D) http://orcid.org/0000-0001-5558-1269

\section{References}

[1] Khasnabis C, Mirza Z, MacLachlan M. Opening the GATE to inclusion for people with disabilities. Lancet. 2015;386: 2229-2230.

[2] United Nations General Assembly. Convention on the rights of persons with disabilities. New York (NY): UN General Assembly; 2006. 
[3] Fuhrer MJ, Jutai JW, Scherer MJ, et al. A framework for the conceptual modelling of assistive technology device outcomes. Disabil Rehabil. 2003;25:1243-1251.

[4] Lenker JA, Scherer MJ, Fuhrer MJ, et al. Psychometric and administrative properties of measures used in assistive technology device outcomes research. Assist Technol. 2005; 17:7-22.

[5] Lenker JA, Harris F, Taugher $M$, et al. Consumer perspectives on assistive technology outcomes. Disabil Rehabil Assist Technol. 2013;8:373-380.

[6] European Commission. Education and training: monitor. Luxembourg City: Publications Office of the European Union; 2017.

[7] National Center for Education Statistics. Digest of education statistics 2016. Washington (DC): U.S. Department of Education; 2018.

[8] Huang I, Sugden D, Beveridge S. Children's perceptions of their use of assistive devices in home and school settings. Disabil Rehabil Assist Technol. 2009;4:95-105.

[9] Watson $A H$, Ito $M$, Smith RO, et al. Effect of assistive technology in a public school setting. Am J Occup Ther. 2010; 64:18-29.

[10] Wynne R, McAnaney D, MacKeogh T, et al. Assistive technology/equipment in supporting the education of children with special educational needs - what works best? Trim (Ireland): National Council for Special Education; 2016.

[11] Hauschildt K, Gwosć C, Netz N, et al. Social and economic conditions of student life in Europe: synopsis of indicators eurostudent 2012-2015. Germany: W. Bertelsmann Verlag GmbH \& Co. KG; 2015. Available from: https://www.uhr.se/ globalassets/_uhr.se/lika-mojligheter/eurostudent/evsynopsi sofindicators.pdf

[12] Riddell S. The inclusion of disabled students in higher education in Europe: progress and challenges. Proceedings of the Italian University Conference of Delegates for Disabilities; 2016 May 12-14; Torino, Italy: University of Turin.

[13] Hadjikakou K, Polycarpou V, Hadjilia A. The experiences of students with mobility disabilities in Cypriot higher education institutions: listening to their voices. Int J Disabil Dev Educ. 2010;57:403-426.

[14] Mullins L, Preyde M. The lived experience of students with an invisible disability at a Canadian university. Disabil Soc. 2013;28:147-160.

[15] Shevlin M, Kenny M, McNeela E. Participation in higher education for students with disabilities: an Irish perspective. Disabil Soc. 2004;19:15-30.

[16] Berggren U, Rowan D, Bergbäck E, et al. Disabled students' experiences of higher education in Sweden, the Czech Republic, and the United States-a comparative institutional analysis. Disabil Soc. 2016;31:339-356.

[17] Sachs D, Schreuer N. Inclusion of students with disabilities in higher education: performance and participation in student's experiences. Disabil Stud Q. 2011;31.

[18] Barnard-Brak L, Lectenberger D, Lan WY. Accommodation strategies of college students with disabilities. Qual Rep. 2010;15:411-429.

[19] Claiborne LB, Cornforth S, Gibson A, et al. Supporting students with impairments in higher education: social inclusion or cold comfort? Int J Inclus Educ. 2011;15:513-527.

[20] Lourens H, Swartz L. Experiences of visually impaired students in higher education: bodily perspectives on inclusive education. Disabil Soc. 2016;31:240-251.
[21] Bernd T, Van Der Pijl D, De Witte LP. Existing models and instruments for the selection of assistive technology in rehabilitation practice. Scand J Occup Ther. 2009;16: 146-158.

[22] de Joode E, van Heugten C, Verhey F, et al. Efficacy and usability of assistive technology for patients with cognitive deficits: a systematic review. Clin Rehabil. 2010;24:701-714.

[23] Kagohara DM, van der Meer L, Ramdoss S, et al. Using iPods ${ }^{\circledR}$ and iPads ${ }^{\circledR}$ in teaching programs for individuals with developmental disabilities: a systematic review. Res Dev Disabil. 2013;34:147-156.

[24] Lorah ER, Parnell A, Whitby PS, et al. A systematic review of tablet computers and portable media players as speech generating devices for individuals with autism spectrum disorder. J Autism Dev Disord. 2015;45:3792-3804.

[25] Perelmutter B, McGregor KK, Gordon KR. Assistive technology interventions for adolescents and adults with learning disabilities: an evidence-based systematic review and metaanalysis. Comput Educ. 2017;114:139-163.

[26] Pino M, Mortari L. The inclusion of students with dyslexia in higher education: a systematic review using narrative synthesis. Dyslexia. 2014;20:346-369.

[27] Moher D, Liberati A, Tetzlaff J, et al. Preferred reporting items for systematic reviews and meta-analyses: the PRISMA statement. Ann Intern Med. 2009;151:264-269.

[28] Leonardi M, Bickenbach J, Ustun TB, et al. The definition of disability: what is in a name? Lancet. 2006;368:1219-1221.

[29] Frantzen KK, Fetters MD. Meta-integration for synthesizing data in a systematic mixed studies review: insights from research on autism spectrum disorder. Qual Quant. 2016; 50:2251-2277.

[30] Gough D, Oliver S, Thomas J. An introduction to systematic reviews. 2nd ed. Los Angeles (CA): Sage; 2017.

[31] Heyvaert M, Maes B, Onghena P. Mixed methods research synthesis: definition, framework, and potential. Qual Quant. 2013;47:659-676.

[32] Thomas J, Harden A. Methods for the thematic synthesis of qualitative research in systematic reviews. BMC Med Res Methodol. 2008;8:45.

[33] Dixon-Woods M, Agarwal S, Jones D, et al. Synthesising qualitative and quantitative evidence: a review of possible methods. J Health Serv Res Policy. 2005;10:45-53.

[34] Lucas PJ, Baird J, Arai L, et al. Worked examples of alternative methods for the synthesis of qualitative and quantitative research in systematic reviews. BMC Med Res Methodol. 2007;7:4.

[35] Mays N, Pope C, Popay J. Systematically reviewing qualitative and quantitative evidence to inform management and policy-making in the health field. J Health Serv Res Policy. 2005;10:6-20.

[36] Hong QN, Pluye P, Bujold $M$, et al. Convergent and sequential synthesis designs: implications for conducting and reporting systematic reviews of qualitative and quantitative evidence. Syst Rev. 2017;6:61.

[37] Pluye P, Robert E, Cargo M, et al. Proposal: a mixed methods appraisal tool for systematic mixed studies reviews. 2011. Available from: http://mixedmethodsappraisaltool public.pbworks.com

[38] Pluye P, Hong QN. Combining the power of stories and the power of numbers: mixed methods research and mixed studies reviews. Annu Rev Public Health. 2014;35:29-45.

[39] Pace R, Pluye P, Bartlett G, et al. Testing the reliability and efficiency of the pilot Mixed Methods Appraisal Tool 
(MMAT) for systematic mixed studies review. Int J Nurs Stud. 2012;49:47-53.

[40] Taylor E, Hignett S. Evaluating evidence: defining levels and quality using critical appraisal mixed methods tools. HERD. 2014;7:144-151.

[41] Chan ZC, Chan YT, Lui CW, et al. Gender differences in the academic and clinical performances of undergraduate nursing students: a systematic review. Nurse Educ Today. 2014; 34:377-388.

[42] Dahan-Oliel N, Shikako-Thomas K, Majnemer A. Quality of life and leisure participation in children with neurodevelopmental disabilities: a thematic analysis of the literature. Qual Life Res. 2012;21:427-439.

[43] Frantzen KK, Lauritsen $M B$, Jørgensen $M$, et al. Parental self-perception in the autism spectrum disorder literature: a systematic mixed studies review. Rev J Autism Dev Disord. 2016;3:18-36.

[44] Husebø AM, Storm M, Våga BB, et al. Status of knowledge on student-learning environments in nursing homes: a mixed-method systematic review. J Clin Nurs. 2018;27: e1344-e1359.

[45] Tsimicalis A, Denis-Larocque G, Michalovic A, et al. The psychosocial experience of individuals living with osteogenesis imperfecta: a mixed-methods systematic review. Qual Life Res. 2016;25:1877-1896.

[46] Malcolm MP, Roll MC. The impact of assistive technology services in post-secondary education for students with disabilities: intervention outcomes, use-profiles, and userexperiences. Assist Technol. 2017;29:91-98.

[47] Malcolm MP, Roll MC. Self-reported assistive technology outcomes and personal characteristics in college students with less-apparent disabilities. Assist Technol. 2017;1-11.

[48] Malcolm MP, Roll MC. Assistive technology outcomes in post-secondary students with disabilities: the influence of diagnosis, gender, and class-level. Disabil Rehabil Assist Technol. 2017;12:857-867.

[49] Ashby CE, Causton-Theoharis J. "Moving quietly through the door of opportunity": perspectives of college students who type to communicate. Equity Excell Educ. 2012;45: 261-282.

[50] Bhardwaj RK, Kumar S. A comprehensive digital environment for visually impaired students: user's perspectives. Libr Hi Tech. 2017;35:542-557.

[51] Christ T. Technology support services in postsecondary education: a mixed methods study. Technol Disabil. 2008; 20:25-35

[52] Floyd KK, Judge SL. The efficacy of assistive technology on reading comprehension for postsecondary students with learning disabilities. Assist Technol Outcomes Benefits. 2012;8:48-64.

[53] Foley AR, Masingila JO. The use of mobile devices as assistive technology in resource-limited environments: access for learners with visual impairments in Kenya. Disabil Rehabil Assist Technol. 2015;10:332-339.

[54] Hanafin J, Shevlin M, Kenny M, et al. Including young people with disabilities: assessment challenges in higher education. High Educ. 2007;54:435-448.

[55] Harshman J, Bretz SL, Yezierski E. Seeing chemistry through the eyes of the blind: a case study examining multiple gas law representations. J Chem Educ. 2013;90:710-716.

[56] Kernohan L. Access opportunities and issues for students with disabilities at one Ontario college. Coll Q. 2008;11: $1-19$.
[57] Kuzu A. The factors that motivate and hinder the students with hearing impairment to use mobile technology. Turk Online J Educ Technol. 2011;10:336-348.

[58] Nelson LM, Reynolds TW. Speech recognition, disability, and college composition. J Postsecond Educ Disabil. 2015; 28:181-197.

[59] Schmitt AJ, McCallum E, Hennessey J, et al. Use of reading pen assistive technology to accommodate post-secondary students with reading disabilities. Assist Technol. 2012;24: 229-239.

[60] Tanners A, McDougall D, Skouge J, et al. Comprehension and time expended for a doctoral student with a learning disability when reading with and without an accommodation. Learn Disabil Multidiscip J. 2012;18:3-10.

[61] Lartz MN, Stoner JB, Stout LJ. Perspectives of assistive technology from deaf students at a hearing university. Assist Technol Outcomes Benefits. 2008;5:72-91.

[62] Smith-Osborne A. Perceived influence of adoption of personal electronic response systems by students with and without disabilities and limited English proficiency in small social work classes. J Technol Hum Serv. 2014;32:54-64.

[63] Stinson MS, Elliot LB, Kelly RR, et al. Deaf and hard-of-hearing students' memory of lectures with speech-to-text and interpreting/note taking services. J Spec Educ. 2009;43: 52-64.

[64] Seale J, Wald M, Draffan E. Exploring the technology experiences of disabled learners in higher education: challenges for the use and development of participatory research methods. J Assist Technol. 2008;2:4-15.

[65] Mosia PA, Phasha N. Access to curriculum for students with disabilities at higher education institutions: how does the National University of Lesotho fare? Afr J Disabil. 2017;6: $1-13$.

[66] Heiman T, Shemesh DO. Students with LD in higher education: use and contribution of assistive technology and website courses and their correlation to students' hope and well-being. J Learn Disabil. 2012;45:308-318.

[67] Hendricks DJ, Sampson E, Rumrill P, et al. Activities and interim outcomes of a multi-site development project to promote cognitive support technology use and employment success among postsecondary students with traumatic brain injuries. NeuroRehabilitation. 2015;37:449-458.

[68] Rice IM, Wong AW, Salentine BA, et al. Differences in participation based on self-esteem in power and manual wheelchair users on a university campus: a pilot study. Disabil Rehabil Assist Technol. 2015;10:102-107.

[69] Wessel RD, Jones D, Blanch CL, et al. Pre-Enrollment considerations of undergraduate wheelchair users and their post-enrollment transitions. J Postsecond Educ Disabil. 2015;28:57-72.

[70] Algood SD, Cooper RA, Fitzgerald SG, et al. Effect of a pushrim-activated power-assist wheelchair on the functional capabilities of persons with tetraplegia. Arch Phys Med Rehabil. 2005;86:380-386.

[71] Frank A, Neophytou C, Frank J, et al. Electric-powered indoor/outdoor wheelchairs (EPIOCs): users' views of influence on family, friends and carers. Disabil Rehabil Assist Technol. 2010;5:327-338.

[72] Hwang CS, Weng HH, Wang LF, et al. An eye-tracking assistive device improves the quality of life for ALS patients and reduces the caregivers' burden. J Mot Behav. 2014;46: 233-238. 
[73] Theeven $P$, Hemmen B, Rings $F$, et al. Functional added value of microprocessor-controlled prosthetic knee joints in daily life performance of Medicare functional classification level-2 amputees. J Rehabil Med. 2011;43:906-915.

[74] Wright FV, Jutai JW. Evaluation of the longer-term use of the David Hart Walker Orthosis by children with cerebral palsy: a 3-year prospective evaluation. Disabil Rehabil Assist Technol. 2006;1:155-166.

[75] Enable Ireland. Assistive technology for people with disabilities and older people: a discussion paper. 2016. Available from: https://www.enableireland.ie/sites/default/files/publication/AT\%20Paper\%20final\%20version.pdf

[76] GDI Hub. Assistive technology scoping research: executive summary. 2018. Available from: https://www.disabilityinnovation.com/uploads/images/GDI-Hub-Assistive-TechnologyScoping-Research.compressed.pdf

[77] Messinger-Willman J, Marino MT. Universal design for learning and assistive technology: leadership considerations for promoting inclusive education in today's secondary schools. NASSP Bull. 2010;94:5-16.

[78] Rose DH, Hasselbring TS, Stahl S, et al. Assistive technology and universal design for learning: two sides of the same coin. In: Edyburn D, Higgins K, Boone R, editors. Handbook of special education technology research and practice. Whitefish Bay (WI): Knowledge by Design Inc.; 2005. p. 507-518.

[79] Scherer MJ, Cushman LA. A functional approach to psychological and psychosocial factors and their assessment in rehabilitation. In: Dittmar SS, Gresham GE, editors. Functional assessment and outcomes measurement for the rehabilitation health professional. Gaithersbug (MD): Aspen Publishers; 1997. p. 57-67.

[80] Scherer M, Sax C, Vanbiervliet A, et al. Predictors of assistive technology use: the importance of personal and psychosocial factors. Disabil Rehabil. 2005;27:1321-1331.

[81] O'Shea A, Kaplan A. Disability identity and use of services among college students with psychiatric disabilities. Qual Psychol. 2017;5:358-379.

[82] Hitchcock C, Stahl S. Assistive technology, universal design, universal design for learning: improved learning opportunities. J Spec Educ Technol. 2003;18:45-52.

[83] Perry J, Beyer S, Holm S. Assistive technology, telecare and people with intellectual disabilities: ethical considerations. J Med Ethics. 2009;35:81-86.

[84] Desmond D, Layton N, Bentley J, et al. Assistive technology and people: a position paper from the first global research, innovation and education on assistive technology (GREAT) summit. Disabil Rehabil Assist Technol. 2018;13:437-444.

[85] Herts KL, Wallis E, Maslow G. College freshmen with chronic illness: a comparison with healthy first-year students. J Coll Stud Dev. 2014;55:475-480.

[86] Britten N, Campbell R, Pope C, et al. Using meta ethnography to synthesise qualitative research: a worked example. J Health Serv Res Policy. 2002;7:209-215.

\section{Appendix 1}

\section{PsycINFO}

1. DE "Assistive Technology" OR DE "Medical Therapeutic Devices" OR DE "Artificial Pacemakers" OR DE "Hearing Aids" OR DE "Cochlear Implants" OR DE "Optical Aids" OR DE "Contact Lenses" OR DE "Prostheses" OR DE "Cochlear
Implants" OR DE "Augmentative Communication" OR DE "Synthetic Speech" OR DE "Mobility Aids"

2. assistive $\mathrm{N} 1$ technol* $\mathrm{OR}$ assistive $\mathrm{N} 1$ equipment $\mathrm{OR}$ assistive N1 product* OR assistive N1 aid* OR assistive N1 device* OR self-help N1 device* OR disability N1 aid* OR empowering $\mathrm{N} 1$ technology OR technical N1 aid* OR sensory N1 aid* OR communication N1 aid* OR audiovisual N1 aid* OR cognitive N1 aid* OR memory N1 aid* OR mobility $\mathrm{N} 1$ aid* OR electronic N1 aid* OR electronic N1 assistive

3. S1 OR S2

4. DE "Disabilities" OR DE “Developmental Disabilities" OR DE "Specific Language Impairment" OR DE "Learning Disabilities" OR DE "Dyslexia" OR DE "Multiple Disabilities" OR DE "Deaf Blind" OR DE "Reading Disabilities" OR DE "Dyslexia"

5. DE "Syndromes" OR DE "Addisons Disease" OR DE "AIDS" OR DE "Autism Spectrum Disorders" OR DE "Balint's Syndrome" OR DE "Battered Child Syndrome" OR DE "Capgras Syndrome" OR DE "Chronic Fatigue Syndrome" OR DE "Cornelia De Lange Syndrome" OR DE "Creutzfeldt Jakob Syndrome" OR DE "Crying Cat Syndrome" OR DE "Culture Bound Syndromes" OR DE "Cushings Syndrome" OR DE "Delirium Tremens" OR DE "Down;s Syndrome" OR DE "Fetal Alcohol Syndrome" OR DE "Fragile X Syndrome" OR DE "Irritable Bowel Syndrome" OR DE "Kleine Levin Syndrome" OR DE "Klinefelters Syndrome" OR DE "Kluver Bucy Syndrome" OR DE "Lennox Gastaut Syndrome" OR DE "Locked-In Syndrome" OR DE "MELAS" OR DE "Menieres Disease" OR DE "Metabolic Syndrome" OR DE "Neuroleptic Malignant Syndrome" OR DE "Organic Brain Syndromes" OR $\mathrm{DE}$ "Posterior Reversible Encephalopathy" OR DE "Prader Willi Syndrome" OR DE "Premenstrual Syndrome" OR DE "Rett Syndrome" OR DE "Senile Dementia" OR DE "Testicular Feminization Syndrome" OR DE "Turners Syndrome" OR DE "Wernicke's Syndrome" OR DE "Williams Syndrome"

6. DE "Congenital Disorders" OR DE "Agenesis" OR DE "Cleft Palate" OR DE "Drug Induced Congenital Disorders" OR DE "Hermaphroditism" OR DE "Microcephaly" OR DE "Prader Willi Syndrome" OR DE "Spina Bifida"

7. DE "Physical Disorders" OR DE "Blood and Lymphatic Disorders" OR DE "Cachexia" OR DE "Cardiovascular Disorders" OR DE "Chronically III Children" OR DE "Digestive System Disorders" OR DE "Endocrine Disorders" OR DE "Genetic Disorders" OR DE "Health Impairments" OR DE "Immunologic Disorders" OR DE "Infectious Disorders" OR $D E$ "Metabolism Disorders" OR DE "Musculoskeletal Disorders" OR DE "Neonatal Disorders" OR DE "Neoplasms" OR DE "Nervous System Disorders" OR DE "Nutritional Deficiencies" OR DE "Respiratory Tract Disorders" OR DE "Sense Organ Disorders" OR DE "Sensory System Disorders" OR DE "Skin Disorders" OR DE "Toxic Disorders" OR DE "Urogenital Disorders" OR DE "Vision Disorders"

8. DE "Neuromuscular Disorders" OR DE "Cataplexy" OR DE "Muscular Dystrophy" OR DE "Myasthenia Gravis" OR DE "Myopathy" OR DE "Paralysis" OR DE "Tourette Syndrome"

9. DE "Spinal Cord Injuries" OR DE "Whiplash"

10. DE "Cerebral Palsy"

11. DE "Hearing Disorders" OR DE "Deaf" OR DE "Deaf Blind"

12. DE "Vision Disorders" OR DE "Balint's Syndrome" OR DE "Blind" OR DE "Deaf Blind" OR DE "Eye Disorders" OR DE "Amblyopia" OR DE "Cataracts" OR DE "Color Blindness" OR DE "Glaucoma" OR DE "Nystagmus" OR DE "Refraction 
Errors" OR DE "Strabismus" OR DE "Tunnel Vision" OR DE "Hemianopia"

13. DE "Communication Disorders" OR DE "Language Disorders" OR DE "Aphasia" OR DE "Echolalia" OR DE "Mutism" OR DE "Specific Language Impairment" OR DE "Speech Disorders" OR DE "Articulation Disorders" OR DE "Dysphonia" OR DE "Stuttering"

14. DE "Cognitive Impairment"

15. S4 OR S5 OR S6 OR S7 OR S8 OR S9 OR S10 OR S11 OR S12 OR S13 OR S14

16. disab* OR impair* OR "deficit"

17. S15 OR S16

18. DE "Higher Education" OR DE "Graduate Education" OR DE "Postgraduate Training" OR DE "Undergraduate Education" DE "College Students" OR DE "College Athletes" OR DE "Community College Students" OR DE "Education Students" OR DE "Junior College Students" OR DE "Nursing Students" OR DE "ROTC Students" OR DE "Postgraduate Students"

19. $A B$ college* $O R A B$ "university" $O R A B$ "universities" $O R$ $A B$ third $N 1$ level $O R A B$ third level $N 1$ education $O R A B$ "post-secondary" $O R A B$ post $N 1$ secondary $O R A B$ "postsecondary" OR $A B$ higher $N 1$ education $O R A B$ undergraduate $\mathrm{N} 1$ student* $\mathrm{OR} A B$ postgraduate $\mathrm{N} 1$ student* $\mathrm{OR}$ $A B$ college $N 1$ student* $O R A B$ university $N 1$ student* $O R$ $A B$ student* $O R A B$ "pupil" $O R A B$ "pupils" $O R A B$ "education"

20. S18 OR S19

21. S3 AND S17 AND S20

\section{Appendix 2}

\section{PubMed}

1. Self-Help Devices [Mesh] OR Speech Recognition Software [Mesh] OR Sensory Aids [Mesh] OR Eyeglasses [Mesh] OR Orthotic Devices [Mesh] OR Artificial Limbs [Mesh] OR Canes [Mesh] OR Walkers [Mesh] OR Dependent ambulation [Mesh]

2. assistive technol* OR assistive aid* OR "assistive equipment" OR assistive product* OR assistive device* OR self-help device* OR disability aid* OR "empowering technology" OR technical aid* OR sensory aid* OR communication aid* OR audiovisual aid* OR cognitive aid* OR memory aid* OR mobility aid* OR electronic aid* OR "electronic assistive technology"

3. \#1 OR \#2

4. Disabled Persons [Mesh] OR Mobility Limitation [Mesh] OR Spinal Cord Injuries [Mesh] OR Spinal Dysraphism [Mesh] OR Cerebral Palsy [Mesh] OR Neuromuscular Diseases [Mesh] OR Neurobehavioural Manifestations [Mesh] OR Neurodevelopmental Disorders [Mesh] OR Cognition Disorders [Mesh] OR Hearing Disorders [Mesh] OR Vision Disorders [Mesh]

5. disab* OR impair* OR "deficit"

6. \#4 OR \#5

7. Universities [Mesh] OR Students [Mesh]

8. college* [tiab] OR "university" [tiab] OR "universities" [tiab] OR "third level" [tiab] OR "third level education" [tiab] OR "post-secondary" [tiab] OR "post secondary" [tiab] OR "postsecondary" [tiab] OR "higher education" [tiab] OR undergraduate student* [tiab] OR postgraduate student* [tiab] OR college student* [tiab] OR university student* [tiab] OR student* [tiab] OR "pupil" [tiab] OR "pupils" [tiab] OR "education" [tiab]
9. $\# 7$ OR \#8

10. \#3 AND \#6 AND \#9

\section{Appendix 3}

\section{CINAHL}

1. (MH "Assistive Technology") OR (MH "Assistive Technology Devices+") OR (MH "Orthopedic Equipment and Supplies+") OR (MH "Sensory Aids+") OR (MH "Eyeglasses+") OR (MH "Prostheses and Implants+") OR (MH "Alternative and Augmentative Communication")

2. assistive $\mathrm{N} 1$ technol* $^{*} \mathrm{OR}$ assistive $\mathrm{N} 1$ equipment $\mathrm{OR}$ assistive N1 product* OR assistive N1 aid* OR assistive N1 device* OR self-help N1 device* OR disability N1 aid* OR empowering $\mathrm{N} 1$ technology OR technical N1 aid* OR sensory N1 aid* OR communication N1 aid* OR audiovisual N1 aid* OR cognitive N1 aid* OR memory N1 aid* OR mobility N1 aid* OR electronic N1 aid* OR electronic N1 assistive

3. $\mathrm{S} 1 \mathrm{OR} 2$

4. (MH "Disabled+") OR (MH "Neurobehavioral Manifestations+") OR (MH "Sensation Disorders+") OR (MH "Child Development Disorders, Pervasive+") OR (MH "Neuro muscular Manifestations+") OR (MH "Neurodegenerative Diseases+") OR (MH "Paralysis+") OR (MH "Spinal Cord Injuries+") OR (MH "Cerebral Palsy") OR (MH "Spina Bifida") OR (MH "Cognition Disorders+")

5. disab* OR impair* OR "deficit"

6. S4 OR S5

7. (MH "College Graduates") OR (MH "Students, College") OR (MH "Colleges and Universities+") OR (MH "Students, Undergraduate") OR (MH "Students, Graduate")

8. $A B$ college* $O R A B$ "university" $O R A B$ "universities" $O R A B$ third $N 1$ level $O R A B$ third level $N 1$ education $O R A B$ "postsecondary" $O R \quad A B$ post $N 1$ secondary $O R \quad A B$ "postsecondary" $O R A B$ higher $N 1$ education $O R A B$ undergraduate $N 1$ student* $O R A B$ postgraduate $N 1$ student* OR $A B$ college $N 1$ student* $O R A B$ university $N 1$ student* $O R$ $A B$ student* $O R A B$ "pupil" $O R A B$ "pupils" $O R \quad A B$ "education"

9. S7 OR S8

10. S3 AND S6 AND S9

\section{Appendix 4}

ERIC

1. MAINSUBJECT.EXACT.EXPLODE("Assistive Technology") OR MAINSUBJECT.EXACT("Augmentative and Alternative Com munication") OR MAINSUBJECT.EXACT.EXPLODE("Audiovisual Aids") OR MAINSUBJECT.EXACT.EXPLODE("Language Aids") OR MAINSUBJECT.EXACT.EXPLODE("Autoinstructional Aids")

2. (assistive NEAR/1 technol*) OR (assistive NEAR/1 equipment) OR (assistive NEAR/1 product*) OR (assistive NEAR/1 aid*) OR (assistive NEAR/1 device*) OR ("self help" NEAR/1 device*) OR (disability NEAR/1 aid*) OR (empowering NEAR/ 1 technology) OR (technical NEAR/1 aid*) OR (sensory NEAR/1 aid*) OR (communication NEAR/1 aid*) OR (audiovisual NEAR/1 aid*) OR (cognitive NEAR/1 aid*) OR (memory NEAR/1 aid*) OR (mobility NEAR/1 aid*) OR (electronic NEAR/1 aid*) OR (electronic NEAR/1 assistive)

3. 1 OR 2

4. MAINSUBJECT.EXACT.EXPLODE(“Disabilities”)

5. disab* OR impair* OR "deficit" 
6. 4 OR 5

7. MAINSUBJECT.EXACT.EXPLODE(“Colleges") OR MAINSUBJECT. EXACT.EXPLODE("College Students") OR MAINSUBJECT. EXACT.EXPLODE("Special Needs Students")

8. $A B$ (college*) $O R \quad A B($ "university") $O R \quad A B$ ("universities") $O R$ $A B$ (third NEAR/1 level) OR $A B$ (third AND (level NEAR/ 1 education)) $O R A B$ ("post-secondary") $O R A B$ (post NEAR/1 secondary) $O R \quad A B$ ("postsecondary") $O R \quad A B$ (higher NEAR/1 education) $O R \quad A B$ (undergraduate NEAR/1 student*) $O R$ $A B$ (postgraduate NEAR/1 student*) OR AB(college NEAR/1 student*) OR $A B$ (university NEAR/1 student*) $O R$ $A B$ (student*) $\quad O R \quad A B$ ("pupil”) $O R \quad A B($ "pupils") $O R$ $A B$ ("education")

9. 7 OR 8

10. 3 AND 6 AND 9

\section{Appendix 5}

Web of science (SSCI)

1. TOPIC: ((assistive NEAR/1 technol*) OR (assistive NEAR/1 equipment) OR (assistive NEAR/1 product*) OR (assistive NEAR/1 aid*) OR (assistive NEAR/1 device*) OR ("self help" NEAR/1 device*) OR (disability NEAR/1 aid*) OR (empowering
NEAR/1 technology) OR (technical NEAR/1 aid*) OR prosthesis OR orthotic* OR (sensory NEAR/1 aid*) OR (communication NEAR/1 aid*) OR facilitated communication OR augmentative communication OR (audiovisual NEAR/1 aid*) OR (visual NEAR/1 aid*) OR (hearing NEAR/1 aid*) OR (cognitive NEAR/1 aid*) OR (memory NEAR/1 aid*) OR (mobility NEAR/1 aid*) OR wheelchair* OR cane* OR walker* OR (electronic NEAR/1 aid*) OR (electronic NEAR/1 assistive))

2. TOPIC: (reading disability OR learning disability OR intellectual impairment OR autism spectrum disorder OR cognitive deficit OR memory disorder OR physical disability OR paralysis OR cerebral palsy OR spinal dysraphism OR spinal cord injury OR sensory dysfunction OR communication disorder OR visual impairment OR hearing impairment OR disab* OR impair* OR deficit)

3. TOPIC: (college* OR "university" OR "universities" OR (third NEAR/1 level) OR (third AND (level NEAR/1 education)) OR "post-secondary" OR (post NEAR/1 secondary) OR "postsecondary" OR (higher NEAR/1 education) OR (undergraduate NEAR/1 student*) OR (postgraduate NEAR/1 student*) OR (college NEAR/1 student*) OR (university NEAR/1 student*) OR student* OR "pupil" OR "pupils" OR "education") 4. \#1 AND \#2 AND \#3 